\title{
Factors Influencing Pregnancy Outcomes in Morogoro Municipality, Tanzania
}

\author{
THEOBALD C. E. MOSHA and NAPENDAELI PHILEMON \\ Department of Food Science and Nutrition, Sokoine University of Agriculture, P.O. Box 3109, Morogoro
}

\begin{abstract}
Neonatal, perinatal and infant mortality rates are still high in developing countries despite national and international efforts to redress this problem. This study was conducted to investigate maternal knowledge and attitudes regarding the risk factors that adversely affect pregnancy outcomes in Morogoro municipality, Tanzania. A longitudinal study was conducted among 157 pregnant women attending antenatal clinics from their second trimesters to term. Socio-economic, demographic, anthropometric, biomedical and obstetric information was collected. Results showed that, majority of the pregnant women ( $>70 \%, n=157)$ were aware of the risk factors that could adversely affect the pregnancy outcomes, however, they did not know the exact mechanisms by which the risk factors acted to cause the adverse effects. Occurrence of risk factors among pregnant women was severe anaemia $-1.4 \%$, smoking (0.6\%), passive smoking (22.9\%), alcohol consumption $(2.5 \%)$, unmarried status (11.5\%), under-age ( $<20$ years) $(17.8 \%)$, over-age ( $>35$ years) $(4.5 \%)$, history of stillbirth (7.0\%), history of caesarean section (3.2\%) and history of miscarriage (2.5\%). Maternal total weight gain in the last two trimesters was $7.76 \mathrm{~kg}$. The average birth weight was $3.05 \mathrm{~kg}$, with male infants being heavier ( $3.14 \mathrm{~kg})$ than their female counterparts $(2.95 \mathrm{~kg})$. The incidence of low birth weight was $11.6 \%$, lower than the national average of $18 \%$. It was concluded from this study that, although most women were aware of the pregnancy risk factors, they lacked the knowledge on how the factors affected the pregnancy outcomes. Occurrence of the pregnancy risk factors was generally low and the pregnancy outcomes were good. It is recommended that, women should be educated more about the pregnancy risk factors and encouraged to begin their antenatal clinic early in pregnancy. A larger study should also be conducted to ascertain the association of the other risk factors with pregnancy outcomes, starting with pregnant women in their first trimester.
\end{abstract}

Keywords: Pregnancy outcome, low birth weight, Apgar score, maternal age, Tanzania

\section{Introduction}

Pregnancy risk factors are all the aspects that endanger the life of the mother and the baby. These factors may include poor nutrition of the woman, child spacing, maternal age (under 15 years and over 35 years), inadequate prenatal care, lifestyle behaviours e.g. smoking, alcohol consumption, drug abuse and unsafe sex, overweight, obesity and poverty (Wardlaw \& Kessel, 2002). A study by Kazaura et al. (2006) reported that, several risk factors influence neonatal mortality. These include parity, maternal age, race, marital status, smoking, birth weight, gestation age, labour complications, antenatal care, previous unfavourable outcomes e.g. stillbirth, neonatal deaths, maternal morbidity e.g. malaria and HIV infection and poor socio-economic conditions. Poor nutritional status during pregnancy has been associated with irreversible damage to the infant brain and central nervous system leading to poor brain development and intelligence. Evidence exits that, obesity and non-communicable diseases e.g. cardiovascular diseases start early in childhood (Wardlaw \& Kessel, 2002).

The major negative pregnancy outcomes include neonatal mortality, low birth weight, stillbirths, malformations of the baby and even death of the mother due to difficulties during delivery (Wardlaw \& Kessel, 2002). It is estimated that, about four million out of 130 million infants born worldwide die during the first four weeks of life and more than three million are stillborns (Kazaura et al., 2006). Recent estimates indicate that, about $98 \%$ of the world neonatal deaths and almost an equal proportion of stillbirths are from developing countries, with the highest proportion occurring in sub-Saharan Africa (Kazaura et al., 2006). In Tanzania, National Bureau of Statistics (NBS) (2005) reported that, neonatal mortality rate was 32 per 1,000 live births, perinatal mortality rate was 42 deaths per 1,000 pregnancies and infant mortality rate was 68 per 1,000 live births. In addition, perinatal deaths are higher in urban than in rural areas i.e. 56 and 38 per 1,000 live births, respectively. 
Low birth weight remains a public health problem in many parts of the world and is associated with a range of heath problems, lasting disabilities and even deaths (March of Dimes, 2009). One-half of low birth weight infants in industrialized countries are born preterm ( $<37 \mathrm{wk}$ gestation), however, in the developing countries these children are born at term but are affected by intrauterine growth retardation that begins early in pregnancy (Ramakrishnan, 2004). A study done by Kidanto et al. (2006) in Dar es Salaam, revealed that, perinatal mortality rate (PMR) was 124 deaths per 1000 live births, which was higher than the national average of 99 deaths per 1000 live births. Prevalence rate of low birth weight was $18 \%$, which was similar to rates in other countries in the region. Different empirical studies in Tanzania have showed high incidences of LBW (10-16\%). According to Kidanto et al. (2006), the mean birth weight in Tanzania is 2978 grams and is lower than the average in developed countries.

Since infant mortality rates are highest during the first four weeks, it is important to put care efforts on the early days of life (Kazaura et al., 2006). To be able to understand the underlying causes poor pregnancy outcomes and the subsequent maternal and perinatal mortality, the Commonwealth Secretariat (2008) recommends detailed studies be conducted to investigate the risk factors that adversely affect pregnancy outcomes in various localities in Tanzania. This study was designed as part of the efforts to understand the risk factors that adversely affect pregnancy outcome in Morogoro municipality. Specifically, this study aimed at assessing the knowledge and attitudes of the pregnant women regarding the pregnancy related risk factors and the occurrence of risk factors among pregnant women in Morogoro municipality. The information generated from this study would help the health personnel in planning appropriate intervention programs to address the problem of poor pregnancy outcomes in Morogoro municipality.

\section{Materials and Methods}

\section{Study area}

Morogoro Municipality is located at latitude $6^{0} 49^{\prime} \mathrm{S}$ and longitude $37^{\circ} 40^{\prime}$ E, approximately $200 \mathrm{~km}$ west of Dar es Salaam. It has a population of 228863 people of whom 115,224 (50.35\%) are females and 113639 (49.65\%) are males (NBS, 2005). Maternal mortality rate in the municipality is 153 per 100,000 live births; infant mortality rate is 74 per 1000 live births while under-five mortality rate is 153 per 1000 live births (Planning Commission \& Morogoro Regional
Commissioners Office, 1997). The municipality has three hospitals, twelve health centres and thirty-six dispensaries. All hospitals, health centres and most of the dispensaries offer antenatal clinic services.

\section{Study design and sampling frame}

A longitudinal study involving pregnant women was conducted over a period of six months from September 2008 through April 2009. Inclusion criteria: all pregnant women attending antenatal clinic in selected health facilities within Morogoro municipality and were in their first or second trimesters of gestation were eligible for the study. Exclusion criteria: all pregnant women who had chronic illnesses such as TB, HIV/AIDS, circle cell disease, hypertension and diabetes were excluded from the study. Likewise, pregnant women who were near term (third trimester) were also excluded from the study.

\section{Sampling technique and sample size}

Using random sampling procedure, two hospitals (Morogoro and Mazimbu hospitals) and three health centres (Mafiga, Shalom and Bigwa health centres) were randomly selected out of seven health centres in the municipality. Pregnant women were thereafter selected purposively (basing on gestational age) from the identified health facilities until the desired number of subjects was reached. The pregnant women were recruited at the second trimester and followed up to term. The number of pregnant women involved in this study was determined by using the WHO (1991) method. The sample size was estimated based on the prevalence rate of low birth weight (the major adverse pregnancy outcome) (Kidanto et al., 2006). The sample size was calculated using the equation:

$$
N=t^{2} \times\left(\begin{array}{lll}
p & \times q) / d^{2}
\end{array}\right.
$$

Where $\mathrm{N}=$ sample size; $\mathrm{t}=$ the margin of error (1.96); $\mathrm{p}=$ expected prevalence of low birth weight (10\%); $\mathrm{q}=1-\mathrm{p}(0.9) ; \mathrm{d}=$ level of precision (5\%). The sample size was therefore 138. An additional sample size of 19 (14\%) was added to take care of attrition. The distribution of the studied women was 63 (Morogoro Regional Hospital), 25 (Mazimbu Hospital), 45 (Mafiga Health Centre), 11 (Shalom Health Centre) and 13 (Bigwa Health Centre).

\section{Data Collection}

Administration of the Questionnaire: A structured questionnaire was formulated to collect information from the subjects. The questionnaire sought information on socio-demographic characteristics, risk factors, biomedical information, 
measurements taken during the study and post delivery information. The questionnare was pretested at a prenatal clinic in Kilosa district hospital. Sections one, two and three of the questionnaire were filled once at the beginning of the study, section four was filled each month while section five was filled after the mother had delivered. The questionnaire was administered to the pregnant women through face-to-face interview during the morning hours.

Measurements taken from the pregnant women: Weights were measured by using a digital weighing scale and recorded to the nearest $0.1 \mathrm{~kg}$. Heights were measured by the use of length board and recorded to the nearest $0.1 \mathrm{~cm}$. Body fat mass was measured using bioelectrical impedence (BIA) machine (Model BF-350, America) and recorded in percent. Fat free mass was obtained by substracting body fat mass from $100 \%$ (i.e 100\% - Fat mass). Haemoglobin levels were determined by using capillary blood samples obtained via a finger prick with a sterile lancet. $\mathrm{Hb}$ concentration was then measured with a HemoCue HB 201+ Haemoglobin photometer (HemoCue AB, Angelholm, Sweden) and recorded to the nearest $0.01 \mathrm{~g} / \mathrm{dl}$. Glucose levels were determined from finger prick capillary blood samples by using a HemoCue Glucose 201+ blood glucose analyser (HemoCue AB, Angelholm, Sweden) and recorded to the nearest $0.01 \mathrm{mmol} / \mathrm{l}$.

Systolic and diastolic blood pressures were taken from the mid-upper-arm of the left hand using sphygmomanometer (Model - ADC Sposphyg 760 Proscope Aneroid; Frank Healthcare Co. Ltd, China) and recorded in $\mathrm{mm} \mathrm{Hg}$. Stethoscope (Model - DT514, Winsun Medical, China) was used to monitor the blood flow. Syphilis test was performed on venous blood samples collected from the pregnant women using venereal disease research laboratory (VDRL) and rapid plasma regain (RPR) tests.

\section{Data Analysis}

Data were compiled, coded and analysed using statistical package for social sciences (SPSS) version 12.5 (SPSS Inc., 2335 Wacker Drive, Chicago, IL 60606). Means, variances and frequencies were used to describe the various pregnancy risk factors. Univariate and multivariate analyses were performed to determine the influence of the various pregnancy risk factors on the pregnancy outcomes. A difference was considered to be significant at $\mathrm{p} \leq 0.05$.

\section{Ethical consideration}

Ethical clearance for using human subjects was obtained from the Sokoine University of Agriculture Human Studies Ethics Committee. Permission was sought from the Morogoro region health authorities to conduct the study in the health facilities. The purpose of the study was clearly explained to the pregnant women. Participants signed a consent form to affirm their willingness to participate in the study. The pregnant women had the liberty to withdraw from the study at any stage, without the fear of retribution.

\section{Results}

\section{Maternal characteristics}

Distribution of the ages of the respondents showed that, $77.7 \%(n=157)$ of the respondents were in the age group $20-35$ years while only $17.8 \%$ were in the age group $15-19$ years. Only a few of the women $(4.5 \%)$ were aged above 35 years (Table 1$)$. Majority of the respondents $(88.5 \%, \mathrm{n}=157)$ were married, while only few $(11.5 \%)$ were singles. Some of the single mothers were still staying with their parents or other family members as dependants. Majority of the women $(74.5 \%)$ had attained primary school education, $15.3 \%$ had secondary education and only a few of them had attained post secondary/ vocational education $(0.6 \%)$ and graduate/post graduate level education $(0.6 \%, \mathrm{n}=157)$. About $8.9 \%$ of the respondents had no formal education.

Table 1: Maternal characteristics of the studied women $(n=157)$

\begin{tabular}{l|l|l|l}
\hline Characteristic & \multicolumn{2}{l}{ Response } & \multicolumn{2}{l}{ Per cent } \\
\hline \multirow{3}{*}{ Maternal age (years) } & $15-19$ & 28 & 17.8 \\
& $20-35$ & 122 & 77.7 \\
Marital status & $>35$ & 7 & 4.5 \\
& Married & 139 & 88.5 \\
Education level & Unmarried & 18 & 11.5 \\
& Informal or none & 14 & 8.9 \\
& Primary & 117 & 74.5 \\
& Secondary & 24 & 15.3 \\
& University & 2 & 1.2
\end{tabular}




\begin{tabular}{l|l|l|l}
\hline Characteristic & \multicolumn{2}{l}{ Response } & \multicolumn{2}{l}{ No. of respondents } & 12.7 \\
& Business & 20 & 10.5 \\
Occupation & Farming & 16 & 10.5 \\
& Employed for wage & 16 & 56.8 \\
& Housewife/homemaker & 90 & 9.5 \\
Average income per month & Self-employed & 15 & 54.1 \\
in US\$ & $7.50-74.91$ & 85 & 40.1 \\
\hline
\end{tabular}

${ }^{1} 1$ US $\$=1335$ Tanzania Shillings

Majority of the pregnant women (56.8\%) were homemakers, while only $8.9 \%$ were employed for wage, $9.6 \%$ were self-employed, $12.7 \%$ were petty traders/businesswomen and $10.5 \%$ were small farmers. Regarding the average monthly income, $54.1 \%(\mathrm{n}=157)$ of the pregnant women had an average monthly income below the minimum government wage of US\$74.9; $40.1 \%$ had a medium income ranging between 75.66 and 374.53 US\$ while only $5.8 \%$ of the respondents had high income above 374.53 US\$ per month.

\section{Frequency of risk factors among the pregnant women}

Table 2 summarizes the frequency of risk factors among pregnant women. Most of the pregnant women $(93 \%, \mathrm{n}=157)$ began their antenatal clinic in the mid of the second trimester ( $18^{\text {th }}$ week). Only $7 \%$ of the women began the antenatal clinics in the first trimester (1 - 12 weeks). About $36.3 \%$ of the pregnant women were primigravida, $31.2 \%$ had second pregnancies while $32.5 \%(\mathrm{n}=157)$ were having third to seventh pregnancies. More than $54.0 \%$, of the pregnant women had their youngest children above 23 months old, while $1.9 \%$ had their youngest children between $18-23$ months of age. Only $7.6 \%$ had their children below 18 months. Results on Table 2 revealed further that, most of the pregnant women (87.3\%) had no history of pregnancy complications. About $12.7 \%$ of the studied women had experienced complications before, whereby $7 \%$ had stillbirth, 3.2\% had caesarean section while $2.5 \%$ had miscarriages. The pregnant women were also asked about their medical history e.g. if they have ever contracted diseases such as TB, diabetes, hypertension or other cardiovascular disease. None of the pregnant women had ever used any type of drugs.

Only one of the pregnant woman reported to smoke while majority of the pregnant women $(99.4 \%, \mathrm{n}=157)$ were not smokers. Out of the 157 pregnant women, $36(22.9 \%)$ had spouses or partners who used to smoke in the rooms. These women could therefore be regarded as passive smokers. Few of the pregnant women $(6.4 \%)$ were consuming alcohol, while majority $(93.6 \%)$ were not taking alcohol. Four out of 157 (2.5\%) pregnant women used to consume alcohol but refrained from it three months before conception. For women who consumed alcohol, the average intake per day was two bottles ca $500 \mathrm{ml}(5.2 \%$ alcohol v/v).

Table 3 data show the antenatal services provided to mitigate the risks of poor pregnancy outcomes. All the pregnant women had their blood pressure determined each month they visited the antenatal care clinics. The average blood pressure level for the second trimester was $67 \mathrm{mmHg}$ (systolic) and $108 \mathrm{mmHg}$ (diastolic) while for the third trimesters was $80 \mathrm{mmHg}$ (systolic) and $120 \mathrm{mmHg}$ (diastolic). The pregnant women also received abdominal examination to determine the length and position of the babies (from 36 week) and also the child's heartbeats (from 20 week). More than $80.0 \%$ of the pregnant women $(n=157)$ had their blood samples taken for analyses of haemoglobin levels and blood groups. More than $85 \%$ of the women were also able to have their urine samples analyzed for albumin. These tests were performed only once during the entire gestation period, unless advised otherwise by the physician. Only few of the pregnant women (18.5\%) received nutrition and family planning education on child spacing and proper feeding during gestation and lactation. Conversely, majority of the women $(96.2 \%)$ received education regarding sexually transmitted diseases, diseases of the reproductive tract system and HIV/ AIDS at the PMTCT centres. All pregnant women enrolled in the PMTCT program were screened for HIV infection. Women who were found to be HIV positive were removed from the study. Women also received VDRL/RPR test. 
Table 2: Occurrence of risk factors among pregnant women $(n=157)$

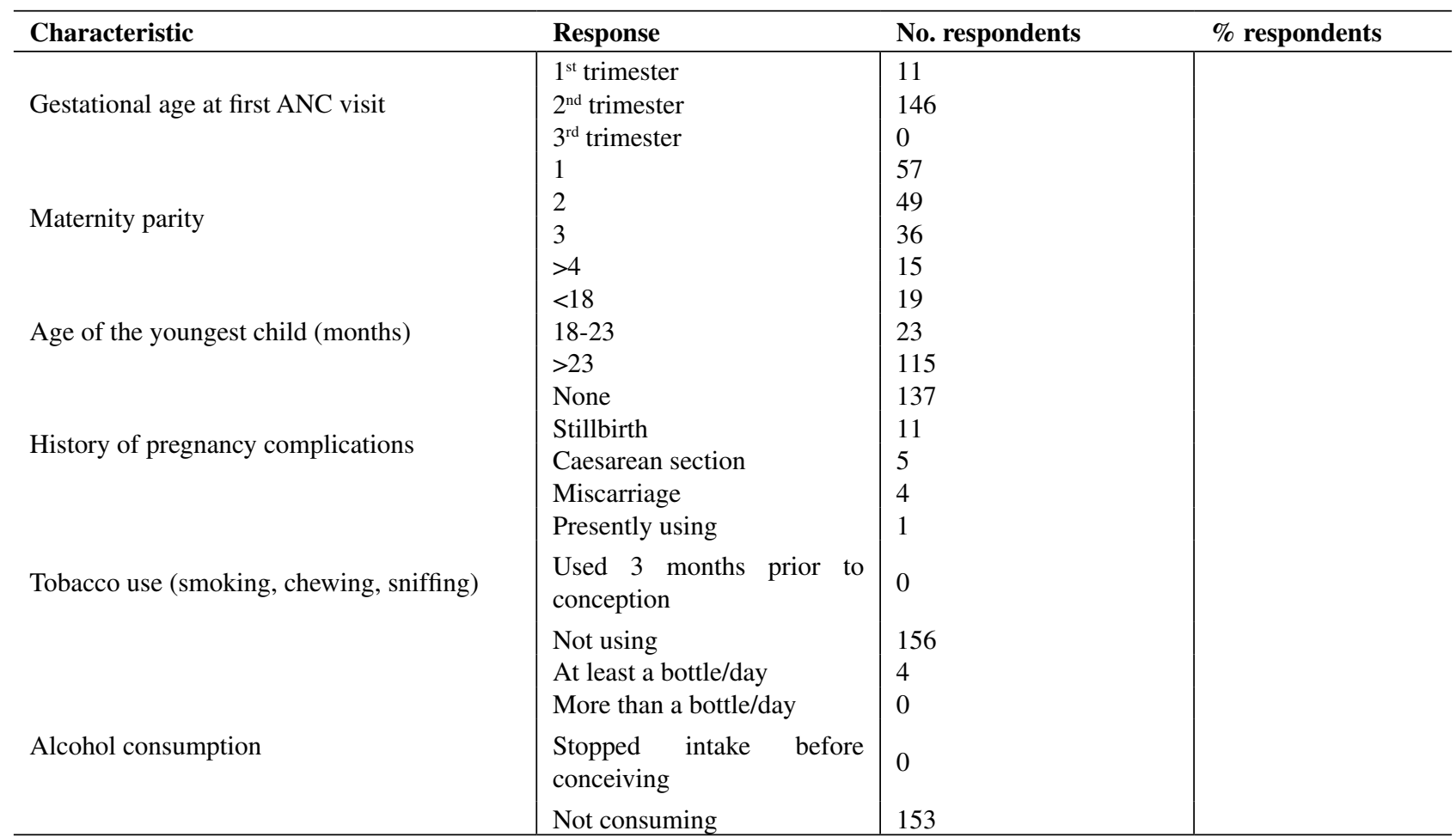

Sulfadoxine pyrimethamine was administered to most of the pregnant women $(84 \%, \mathrm{n}=157)$ at the $20^{\text {th }}$ and $35^{\text {th }}$ weeks of gestation as part of the intermittent preventive treatment (IPT) programme (Table 3). Women who developed malaria were also given a full course of treatment. The pregnant women were also given an offer of insecticide treated mosquito nets at a $50 \%$ subsidized rates. Out of the 152 pregnant women, 97 (64\%) were able to buy the insecticide treated mosquito nets.

\section{Knowledge and attitude regarding the risk factors}

Most of the pregnant women were aware of the risk factors that affect pregnancy outcomes such as smoking, alcohol consumption, drug use, poor nutrition, child spacing, maternal age, antenatal care and unsafe sex. However, some women could not give the details of the risk factors while others mentioned wrong effects. A large proportion of the studied women $(79.6 \%, \mathrm{n}=157)$ knew that tobacco use (smoking or chewing) during pregnancy could lead to adverse pregnancy outcomes. Only $20.4 \%$ of the pregnant women knew that tobacco use especially cigarette smoking could lead to harmful effects to the pregnant woman and the unborn baby. More than $60 \%$ of the women did not know the exact effects that tobacco use may cause to the mother and the unborn baby. Only $12.7 \%$ of the respondents knew correctly the health hazards of tobacco use to a pregnant woman. Health hazards mentioned included pre-term delivery, spontaneous abortion, LBW and cancer.

Most of the pregnant women involved in this study $(42.7 \%, \mathrm{n}=157)$ were not aware of the adverse effects of alcohol intake to the unborn child. Some women $(28 \%)$ had the understanding that alcohol consumption during pregnancy was not good but did not know the exact effects that alcohol could cause. Only $29.3 \%$ of the women knew the effect that alcohol has on the unborn child. A good number of the pregnant women $(73.2 \%$, $\mathrm{n}=157$ ) claimed to know the adverse effects of drugs (marijuana, cocaine, mandrax, opium) during pregnancy to both the mother and the baby, however, only $49.7 \%$ were able to tell the correct effects of these drugs. Adverse pregnancy outcomes that were associated with drug use included; poor health status, small babies, miscarriage, pre-term delivery, brain damage, stillbirth, deformities of the child, mental retardation and reduced weight. Majority of the studied women $(63.7 \%)$ knew the right types of foods they were supposed to eat during pregnancy. More than $30 \%$ of the women pointed out fruits and vegetables as important foods to enhance their iron status while $63.7 \%$ named meet, beans, lentils, whole cereals and vegetables as important foods to improve the general health. 
Table 3: Antenatal services provided to mitigate the risks of poor pregnancy outcomes

\begin{tabular}{llll}
\hline Service & Yes & No & Total \\
\hline Blood pressure examination & 157 & 0 & 157 \\
Abdominal examination & 157 & 0 & 157 \\
Asked about medical history & 29 & 128 & 157 \\
Blood sample collected for VDRL/RPR tests ${ }^{1}$ & 157 & 0 & 157 \\
Urine sample taken for laboratory analyses & 157 & 8 & 157 \\
Tetanus toxoid injection given at least once & 149 & 0 & 157 \\
HIV Status screened & 157 & 128 \\
Advised on diet and nutrition & 29 & 157 \\
Given intermittent preventive treatment of malaria (IPTM) & 132 & 25 & 157 \\
Family planning education & 49 & 108 \\
Advised on STI's, HIV and AIDS & 157 & 0 & 157 \\
Advised on what to do in case of emergency & 157 & 0 & 157 \\
\hline
\end{tabular}

${ }^{1}=$ VDRL $/$ RPR $=$ Venereal Disease Research Laboratory/Rapid Plasma Reagent

About $3.2 \%$ of the women had no idea about the importance of diet and nutrition for the pregnant woman. Knowledge and attitude of the pregnant women regarding the effects of child spacing on the pregnancy outcomes indicated that, most women (70.7\%) did not know that closely spaced births could lead to harmful effects to the mother and the unborn child. Some women $(14 \%, \mathrm{n}=157)$ were not aware that, there was association between child spacing and poor pregnancy outcomes. Only $15.3 \%$ of the pregnant women knew that poor maternal health, intra-uterine growth retardation and low birth weight were the major adverse outcomes of closely spaced pregnancies.

Regarding the appropriate age for conception, most women $(45.9 \%)$ pointed out that age 18-35 years was appropriate while $39.6 \%$ of the women stated that age $20-35$ years was the best. Only $7.6 \%$ of the pregnant women sated that conception at the age of 35 years and above did not carry any risk for poor pregnancy outcome. Likewise, $9.6 \%$ of the pregnant women did not understand whether conception age had any risk to the mother and the rowing baby. Almost all women $(97.5 \%)$ admitted that antenatal care was important for regular monitoring of the mother's health and the baby's condition. Only a few women $(2.5 \%, \mathrm{n}=157)$ did not know the importance of the antenatal care, and this could be due to the fact that, they were primigravida. Majority of the pregnant women $(98.1 \%)$ knew the importance of protecting themselves against sexually transmitted infections and the dangers of having multiple sex partners.

\section{Pregnancy outcomes}

The average monthly weight gain was $1.35 \mathrm{~kg}\left(4^{\text {th }}\right.$ month), $1.34 \mathrm{~kg}\left(5^{\text {th }}\right.$ month $)$ and $1.11 \mathrm{~kg}$ ( $6^{\text {th }}$ month $)$. The average weight gain during the second trimester was therefore $3.8 \mathrm{~kg}$. In the third trimester, the average monthly weight gain was $1.11 \mathrm{~kg}$ ( $7^{\text {th }}$ month $)$, $1.11 \mathrm{~kg}$ ( $8^{\text {th }}$ month $)$ and $1.74 \mathrm{~kg}$ ( $9^{\text {th }}$ months $)$. On average, the weight gain during the third trimester was $3.96 \mathrm{~kg}$. The total mean weight gain in the last two trimesters of gestation was $7.76 \mathrm{~kg}$ (range 5.67 $-14.35 \mathrm{~kg}$ ). Only 11 out of 157 pregnant women $(8.9 \%)$ gained $12 \mathrm{~kg}$ or more during the second and third trimesters (Table 4).

The pregnant women gained an average of $5.26 \%$ body fat mass from the second trimester to term. The average maternal height was 1.56 meters, ranging from 1.4 to 1.73 meters. Majority of the women $(81.3 \%, \mathrm{n}=112)$ were above the 1.51 meters, which is the height associated with good pregnancy outcomes. Most of the studied women $(67.5 \%, \mathrm{n}=$ 112) had $\mathrm{Hb}$ levels above $11 \mathrm{~g} / \mathrm{dl}, 32.5 \%(\mathrm{n}=112)$ had $\mathrm{Hb}$ below the cut off point $(11 \mathrm{~g} / \mathrm{dl})$ to indicate anaemia while $1.4 \%$ had $\mathrm{Hb}$ levels indicating severe anaemia $(<7.0 \mathrm{~g} / \mathrm{dl})$. The average $\mathrm{Hb}$ level for the pregnant women was $12.4 \mathrm{~g} / \mathrm{dl}$ (range $5.90-15.50 \mathrm{~g} /$ dl). All women, whose $\mathrm{Hb}$ levels were below $11 \mathrm{~g} /$ $\mathrm{dl}$, were required to take iron-folate supplement and also advised to eat generous amounts of fruits and vegetables to boost their iron levels. 
Majority of the pregnant women $(98.2 \%$, $\mathrm{n}=112$ ) had blood pressure below $80 / 140 \mathrm{mmHg}$ (systolic/diastolic), which is the lowest cut off point for the classification of normal blood pressure. Only two out of 112 women (1.8\%) had elevated blood pressure above normal. Majority of the pregnant women were therefore out of risks of hypertension. None of the women in the studied group was diagnosed with elevated levels of glucose. From the results, there was no high risk of diabetes and the associated complications.

Table 4: Maternal Characteristics and Birth Outcomes

\begin{tabular}{|c|c|c|}
\hline Variable & Mean \pm SD & Range \\
\hline Maternal age & $24.9 \pm 5.49$ & $15-42$ \\
\hline Parity & $2.21 \pm 1.28$ & $1-7$ \\
\hline Initial gestation age (weeks) & $18.99 \pm 2.66$ & \\
\hline Haemoglobin level (g/dl) & $12.40 \pm 1.60$ & \\
\hline Total weight gain $(\mathrm{kg})$ & $7.76 \pm 2.29$ & \\
\hline $2^{\text {nd }}$ trimester & $3.80 \pm 1.27$ & \\
\hline $3^{\text {rd }}$ trimester & $3.96 \pm 1.32$ & \\
\hline Total fat mass gain & $5.26 \pm 2.39$ & \\
\hline $2^{\text {nd }}$ trimester & $1.96 \pm 0.76$ & \\
\hline $3^{\text {rd }}$ trimester & $3.30 \pm 1.63$ & \\
\hline $\begin{array}{l}\text { Blood pressure }(\mathrm{mmHg}) \text { overall average } \\
\text { Systolic }\end{array}$ & $79 \pm 10$ & $70-85$ \\
\hline Diastolic & $135 \pm 9$ & $127-145$ \\
\hline $\begin{array}{l}\text { Blood pressure in } 2^{\text {nd }} \text { trimester } \\
\text { Systolic }\end{array}$ & $69 \pm 11$ & $60-81$ \\
\hline Diastolic & $127 \pm 14$ & 119-139 \\
\hline Blood in $3^{\text {rd }}$ trimester & $73 \pm 10$ & $70-88$ \\
\hline Diastolic & $132 \pm 12$ & 130-149 \\
\hline Final gestation & $37.87 \pm 1.98$ & $28-42$ \\
\hline Birth weight (overall) & $3.05 \pm 0.51$ & $1.7-4.8$ \\
\hline Birth weight for girls & $2.95 \pm 0.43$ & $2.1-3.6$ \\
\hline Birth weight for boys & $3.14 \pm 0.57$ & $1.8-4.8$ \\
\hline
\end{tabular}

Regarding malaria, most of the pregnant women $(64.8 \%, \mathrm{n}=112)$ received intermittent preventive treatment for malaria at the $20^{\text {th }}$ and $35^{\text {th }}$ weeks of gestation. About $35.2 \%(n=112)$ of the pregnant women contracted at least one bout of malaria during gestation period and were given a full course of treatment. The average gestational age at delivery observed in this study was 37.87 weeks. Babies delivered before 37 weeks are termed "premature" and are often small-for-gestationage (SGA) and/or low in birth weight. Pre-mature delivery was therefore not a major problem among the pregnant women involved in this study. Most of the women $(97.3 \%, \mathrm{n}=112)$ had a normal delivery i.e. spontaneous vaginal delivery. Two of the mothers required vacuum extraction due to pelvic obstruction, thirteen women had to undergo episiotomy, and three others $(2.7 \%, \mathrm{n}=112)$ had to undergo caesarean section. Women who had to undergo caesarean section had no history of maternal complications, but one of them was a primigravida and the other one was an over-age mother ( $>35$ years).

The state of most of the infants was good, with only few children in bad condition. There were four stillbirths of whom three were fresh stillbirths while one was a macerated stillbirth. Out of the remaining 108 infants, only one scored fairly low in the Apgar scale $(4-6)$, while the others scored normal (7-10) in both the first and the fifth minutes. The mean birth weight of children in this study was $3.05 \mathrm{~kg}$. Male infants were heavier than their female counterparts. The average birth weight for males was $3.14 \mathrm{~kg}$ while that of their girl counterparts was $2.95 \mathrm{~kg}$. The incidence of low birth weight in this study was $11.6 \%$. There were three $(2.7 \%, \mathrm{n}=$ 
112) macrosomic infants (babies who weighed $\geq 4.5$ $\mathrm{kg}$ ) and two of these were born to obese mothers. The birth weight distribution was negatively skewed to the right (Figure 1) with majority of the infants having birth weight of more than $2.5 \mathrm{~kg}$.

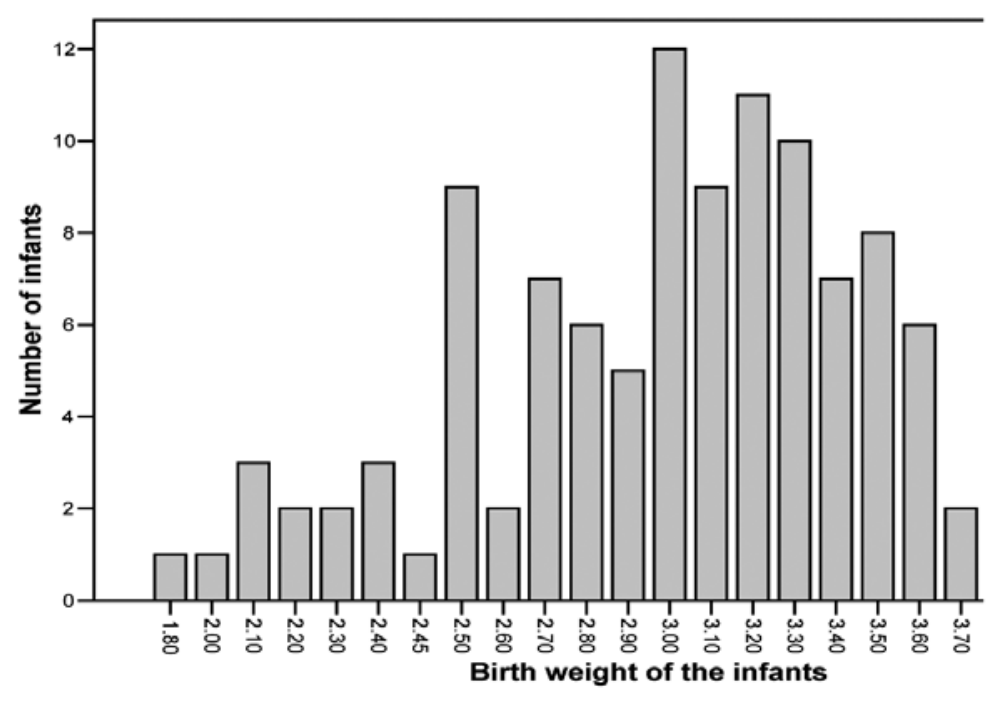

Figure 1: Distribution of birth weights of the infants

\section{Association between risk factors and the pregnancy outcomes}

Table 5 shows the association between the pregnancy outcome (infant birth weight as a dependent variable) and some of the risk factors. Maternal weight gain during the second and third trimesters, haemoglobin level and maternal height had strong ( $p$ $\leq 0.05)$ association with infant birth weight. Other variables such as maternal age, parity, maternal education level, smoking, passive smoking, alcohol consumption, gestational age at delivery, malaria infection during gestation and fat mass did show strong association $(P>0.05)$ with birth weight of the infants.

\section{Table 5: Regression analysis when the dependent variable is birth weight $(N=112)$}

\begin{tabular}{lllll}
\hline Independent & Coefficient & Standard error & t-value & Significance \\
Constant & -3.299 & 1.335 & -2.471 & 0.015 \\
Maternal age & -0.002 & 0.012 & -0.139 & 0.890 \\
Education level & -0.042 & 0.053 & -0.799 & 0.426 \\
Alcohol consumption & -0.032 & 0.167 & -0.192 & 0.848 \\
Smoking & -0.147 & 0.481 & -0.307 & 0.760 \\
Passive smoking & -0.046 & 0.110 & -0.422 & 0.674 \\
Parity & 0.052 & 0.051 & 1.034 & 0.304 \\
Maternal total weight gain & 0.044 & 0.019 & 2.292 & 0.024 \\
Maternal total fat mass gain & 0.002 & 0.020 & 0.084 & 0.933 \\
Hemoglobin level & 0.024 & 0.008 & 3.091 & 0.003 \\
Maternal blood pressure & 0.138 & 0.343 & 0.402 & 0.689 \\
Maternal height & 0.024 & 0.007 & 3.522 & 0.001 \\
Gestational age & 0.014 & 0.023 & 0.600 & 0.550 \\
Malaria infection & 0.052 & 0.051 & 1.034 & 0.304 \\
\hline
\end{tabular}




\section{Discussion}

Maternal characteristics influence pregnancy outcomes. According to Stewart et al. (2007), the appropriate age range to conceive without risks for undesirable outcomes is $20-35$ years. Under-age (below 19 years) and over-age mothers (above 35 years) were at increased risk of poor pregnancy outcomes such as pre-term, small for gestation and low birth weight babies and high neonatal mortality (Stewart et al., 2007). Low education level has indirect effects on the understanding of nutrition and food aspects as well as improvement of the socio-economic conditions (Walraven et al., 1997). Maternal education level therefore influences the food choices and feeding patterns of family members. Majority of the women in this study had attained only primary level education. Marital status has been reported to influence pregnancy outcome (Auger et al., 2008).

Distribution of the average monthly income indicated that, more than half of the women had incomes that were below the minimum government wage of U\$ 74.9. Low income adversely affects food and nutrition security, thus increasing the risk for poor pregnancy outcomes. Tobacco use, alcohol intake and drug use are some of the lifestyle behaviours that have been reported to cause poor pregnancy outcome (Cogswell et al., 2003; Bloch et al., 2008). According to Wardlaw \& Kessel (2002) excess alcohol intake may lead to spontaneous abortion, developmental defects, foetal growth retardation and malformations because the excess alcohol reaches the foetus. Other harmful effects of alcohol on the infants include small head size, low birth weight and low birth length (Williamson, 2006). Use of drugs during pregnancy has been associated with adverse effects on the foetus such as pre-term birth, undersized head and body, physical malformations, brain and nervous system damage (Wardlaw \& Kessel, 2002).

Sexually transmitted infections such as syphilis and HIV/AIDS have been associated with poor pregnancy outcomes including spontaneous abortion, stillbirth, pre-term birth, low birth weight, postpartum sepsis, neonatal pneumonia, neonatal blindness and congenital infections (Msuya et $a l$. , 2009). Time interval between pregnancies strongly influences the outcome of the subsequent pregnancies. Short birth interval does not give the mother enough time to recuperate from the nutritional burden of the previous pregnancy, which may lead to poor pregnancy outcomes (Dewey \& Cohen, 2007). Good pregnancy outcomes are expected when there is a gap of at least $18-$ 23 months between the consecutive pregnancies (Wardlaw \& Kessel, 2002).

The mean $\mathrm{Hb}$ concentration observed among pregnant women in this study was $12.4 \mathrm{~g} / \mathrm{dl}$. Similar levels have been reported among pregnant women in other studies (Hinderaker et al. 2001; Massawe et al. 2002). Hemoglobin levels indicate the oxygen carrying capacity of the blood (Lloyd \& Lewis, 1996). Evidence exits that low Hb levels during pregnancy leads to reduced iron stores, causing infantile anaemia before the age of six months (Allen, 2000). According to WHO/UNICEF/ UNU (2001), the Hb cut-off concentration that is used to define anaemia in pregnancy is $11.0 \mathrm{~g} / \mathrm{dL}$. In light of the above, about one-third of the pregnant women involved in this study were anaemic and out of these, $1.4 \%$ were severely anaemic.

Malaria has been widely reported to cause poor pregnancy outcome (Jamison et al., 1993; Lindsay et al., 2000; Ansell et al., 2002). Malaria infects the placenta making it unable to provide sufficient oxygen and nutrients to the foetus, leading to a range of adverse effects (CDC, 2004). Some of the adverse effects of malaria on pregnancy outcome include severe anaemia, poor foetal growth, llow birth weight, pre-term delivery, miscarriage, and stillbirth. The low prevalence of malaria observed in this study could be attributed to a relatively high coverage of intermittent preventive treatment of malaria and the wide use of insecticide treated mosquito bed nets. Apgar score is a test to evaluate a newborn's physical condition one minute and five minutes after delivery (Hirsch, 2008). Apgar scores $1-3$ indicate that the child is in critical state and requires life supporting services, scores 4 -6 indicate the child is in fair state and may need attention while scores $7-10$ indicate the child is normal and well adapting to the environment. In this study, all children were well and only one child had difficulties to adapt to the environment and required medical attention.

According to IOM (2009), the recommended weight gain during the last two trimesters should be in the range of $7.2-12.0 \mathrm{~kg}$ with overweight/obese women gaining the lower weight of $7.2 \mathrm{~kg}$ and the underweight women gaining the upper weight in the range $(12 \mathrm{~kg}$ ) (Williamson, 2006). In this study, the average weight gain during the last two trimesters was in the lower side of the recommended weight gain range. Overall, women involved in this study gained less weight than recommended for all trimesters. The weight gain in the last two trimesters observed in this study $(7.76 \mathrm{~kg})$ was higher than 
that reported by Nyaruhucha et al. (2006). Only 27 women $(17.2 \%)$ of the 157 pregnant women gained $9.6 \mathrm{~kg}$ and above as recommended by the IOM (2009) for women with normal BMI.

The average maternal height was 1.56 meters. The average maternal height that has been associated with good pregnancy outcomes is $>1.51$ meters (Kirchengast \& Hartmann, 2007). In this study, majority of the women had heights above the recommended one. Short women are more likely to have a small pelvis, which can lead to dystocia with foeto-pelvic disproportion or shoulder dystocia. In addition, short women are more likely to have preterm labour and intrauterine growth retardation (Pilotto et al., 1993). According to Kirchengast \& Hartmann (2007) the prevalence of Caesarian section in shorter women is higher than among those with average height. A study by Shirima \& Kinabo (2005) also reported increased risk of caesarean sections among women of short stature.

The average gestational age at delivery in this study was 37.87 weeks. An earlier study conducted in Morogoro reported a relatively average shorter gestational age (Nyaruhucha et al., 2006). Babies delivered before 37 weeks are termed "premature" and are often small-for-gestation-age (SGA) and/or low in birth weight. The birth weight of children in this study was $3.05 \mathrm{~kg}$. This birth weight was slightly higher than that was reported by Nyaruhucha et al. (2006), but lower than reported in an earlier study (Kinabo, 1993; Nyaruhucha \& Msimbe, 1993). It was observed in this study that, prevalence rate of low birth weight was $11.6 \%$. Higher prevalence rates of low birth weights have been reported from studies in Tanzania (Kinabo, 1993; Walraven et al., 1997; Kidanto et al., 2006).

The association between the pregnancy outcome (infant birth weight as a dependent variable) and some of the risk factors showed that maternal weight gain $>7.76 \mathrm{~kg}$ during the second and third trimester, maternal $\mathrm{Hb}$ level of $12.4 \mathrm{~g} / \mathrm{dL}$ and maternal height $>1.51 \mathrm{~m}$ were the strongest determinants of birth weights. Similar findings have been reported by Shirima \& Kinabo (2005). Inadequate weight gain during pregnancy usually results in low birth weight, which increases the infant's risk of dying (Linkages, 2004). Furthermore, Ramakrishnan, (2004) reported several studies with evidence that iron supplementation to boost $\mathrm{Hb}$ level had a positive effect on birth weight. Other variables such as maternal age, parity, maternal education level, smoking, passive smoking, alcohol consumption, gestational age at delivery, malaria infection during gestation and fat mass did not show strong association with the birth weight of the infants.

This study had a number of limitations. The data reported in this study were collected during the second and third trimesters only and did not cover the entire gestation period. Most pregnant women reported for their antenatal clinic at the mid or towards the end of the second trimester. In light of the foregoing, some of the findings reported in this study could have been different if the data would have been collected from the first trimester.

It was concluded from this study that, majority of the pregnant women were aware of the risk factors that could influence pregnancy outcomes, however, they did not know the exact mechanisms by which the factors acted to cause the adverse effects. It was also revealed that, majority of the pregnant women received all services that were critical to ensure good pregnancy outcomes. Occurrence of most of the risk factors among the pregnant women was generally low and pregnancy outcomes in Morogoro Municipality were generally good. Out of the risk factors, maternal height, maternal total weight gain during the last two trimesters and haemoglobin concentrations showed the strongest association with the infant birth weights. It is recommended that, women should be educated more about the pregnancy risk factors and encouraged to begin their antenatal clinic early in pregnancy. A larger study should also be conducted to ascertain the association of the other risk factors with pregnancy outcomes, starting with pregnant women in their first trimester.

\section{Acknowledgements}

The authors acknowledge with thanks the financial support provided by the Sokoine University of Agriculture, Morogoro. We also extend many thanks to the pregnant women and their infants for generously accepting to participate in this study. Thanks are also due to the Morogoro Region health authorities for granting us permission to carry out the study in the Regional hospital and in the health centres and for providing some logistical support.

Received 25 February 2010
Revised 10 September 2010
Accepted 12 September 2010

\section{References}

Allen, L.H. (2000) Anemia and iron deficiency: effects on pregnancy outcome. American 
Journal of Clinical Nutrition 71 (Suppl), 1280 - 1284.

Ansell, J., Hamilton, K., Pinder, M., Walraven, G. \& Lindsay, S. (2002) Short range attractiveness of pregnant women to Anopheles gambiae mosquitoes. Transactions of the Royal Society of Tropical Medicine and Hygiene. 96, 113 - 116.

Auger, N., Daniel, M., Platt, R.W., Cheng Luo, Z., Wu, Y \& Choinière, R. (2008) The joint influence of marital status, inter-pregnancy interval, and neighbourhood on small for gestational age birth: a retrospective cohort study. BMC Pregnancy and Childbirth 8, 7.

Bloch, M., Althabe, F., Onyamboko, M., KasebaSata, C., Castilla, E.E., Freire, S., Garces, A.L., Parida, S., Goudar, S.S., Kadir, M.M., Goco, N., Thornberry, J., Daniels, M., Bartz, J., Hartwell, T., Moss, N., \& Goldenberg, R. (2008) Tobacco use and second-hand smoke exposure during pregnancy: an investigative survey of women in 9 developing nations. American Journal of Public Health 98, 87 - 96.

CDC (2004) Malaria during pregnancy. Centre for Diseases Control and Prevention, [http:// www.cdc.gov/malaria.htm] site visited on 20/6/2009.

Cogswell, M.E., Weisberg, P. \& Spong, C. (2003) Cigarette Smoking, Alcohol Use and Adverse Pregnancy Outcomes: Implications for Micronutrient Supplementation. Journal of Nutrition 133, 1722S-1731S.

Commonwealth Secretariat (2008) Maternal Morbidity: An Overview and a Tanzania Case Study. [http://www.unfpa.org/] site visited on 18/1/2009.

Dewey, K.G. \& Cohen, R.J. (2007) Does birth spacing affect maternal or child nutritional status? A systematic literature review. Maternal and Child Nutrition 3, 151-173.

Hinderaker, S.G., Olsen, B.E., Bergsjo, P., Lie, R.T., Gacheka, P. \& Kvale, G. (2001) Anaemia in pregnancy in the highlands of Tanzania. Acta Obstetricia et Gynecologica Scandinavica. 80, $18-26$.

Hirsch, L. (2008) What is Apgar score. [http:// kidshealth.org/parent/pregnancy_newborn/ apgar_score.html] site visited on 4/2/2009.

IOM (2009) Institute of Medicine of the National Academy (2009). Weight gain during pregnancy: Re-examining the guidelines. Website: www.nap. edu/pregnancyweightgain. Site visited 08/09/2009.

Jamison, D., Mosley, W.H., Measham, A. \& Bobadilla, J.L. (1993) Disease Control Priorities in Developing Countries. New York. Oxford University Press. Pp 12-48.

Kazaura, M.R., Kidanto, H.L. \& Massawe, S.N. (2006) Levels, trends and risk for early neonatal mortality at Muhimbili National Hospital, Tanzania, 1999-2005. East African Journal of Public Health 3, 10 -13.

Kidanto, H.L., Massawe, S.N., Nystrom, L. \& Lindmark, G. (2006) Analysis of Perinatal mortality at a teaching hospital in Dar es Salaam, Tanzania, 1999-2003. Africa Journal of Reproductive Health 10, 72 - 80.

Kinabo, J. (1993) Seasonal variation of birth weight distribution in Morogoro, Tanzania. East Africa Medical Journal 70, 752 - 755.

Kirchengast, S. \& Hartmann, B. (2007) Short stature is associated with an increased risk of caesarean deliveries in low risk population. Acta Medica Lituanica 14), 1 - 6.

Lindsay, S. Ansell, J., Selman, C., Cox, V., Hamilton, K. \& Walraven, G. (2000) Effect of pregnancy on exposure to malaria mosquitoes. Lancet 355, 1972.

Linkages (2004) Maternal Nutrition during pregnancy and lactation. [http://www. linkagesproject.org] site visited on 4/6/2009.

Lloyd, C. \& Lewis, V. (1996) Diseases associated with pregnancy. In: Bennett, V.R. \& Brown, I.K. (Eds). Myles Textbook for Midwives. $12^{\text {th }}$ Edn. Churchill Livingstone, Edinburgh. Pp 333 - 364.

March of Dimes (2009) Low birth weight. [http:// www.marchofdimes.com/] site visited on 4/2/2009.

Massawe, S.N., Urassa, E.N., Nystrom, L \& Lindmark, G. (2002) Anaemia in women of reproductive age in Dar es Salaam, Tanzania. East African Medical Journal 79, $461-466$.

Msuya, S. E., Uriyo, J., Hussain, A., Mbizvo, E. M., Jeansson, S., Sam, N. E \& Stray-Pedersen, B. (2009) Prevalence of sexually transmitted infections among pregnant women with known HIV status in northern Tanzania. Reproductive Health Journal 6, 4 - 7.

NBS (2005) Tanzania Demographic and Health Survey 2004-05. Dar es Salaam, Tanzania: National Bureau of Statistics and ORC Macro. 
Nyaruhucha, C.N.M. \& Msimbe, H.P. (1993) Some factors affecting birth weights in Morogoro, Tanzania. East Africa Medical Journal 70, $749-751$

Nyaruhucha, C.N.M., Msuya, J.M., Ngowi, B. \& Gimbi, D.M. (2006) Maternal weight gain in second and third trimesters and their relationship with birth weights in Morogoro Municipality, Tanzania. Tanzania Health Research Bulletin 8, 41 - 44.

Pilotto, R.F., Magna, L.A. \& Beiguelman, B. (1993) Factors influencing human birth weight in normal pregnancy: a prospective study in a Brazilian University Hospital. Brazilian Journal of Genetics 16, 457 - 469.

Planning Commission \& Morogoro Regional Commissioners Office (1997). Morogoro Region Socio-Economic Profile. Government Printers, Dar es Salaam.

Ramakrishnan, U. (2004) Nutrition and low birth weight: from research to practice. American Journal of Clinical Nutrition 79, 17- 21.

Shirima, C.P. \& Kinabo, J.L. (2005) Nutritional status and birth outcomes of adolescent pregnant girls in Morogoro, Coast and Dar es Salaam regions, Tanzania. Nutrition 21, $32-38$.

Stewart, C.P., Katz, S.K., LeClerq, S.C., Shrestha, S.R., West, K.P. \& Christian, P. (2007) Preterm delivery but not intrauterine growth retardation is associated with young maternal age among primiparae in rural Nepal. Maternal and Child Nutrition 3, 174 - 185.

Walraven, G.E.L., Mkanje, R.J.B., van Asten, H.A.G.H., van Roosmalen, J., van Dongen, P.W.J. \& Dolmans, W.M.V. (1997) The aetiology of low birth weight in rural area of Tanzania. Tropical Medicine and International Health 2, 558 - 567.

Wardlaw, G. M \& Kessel, M. W. (2002) Perspectives in Nutrition. $5^{\text {th }}$ Ed. Mc Graw Hill. Boston Burr Ridge. Pp 157 - 198.

WHO (1991) Sample size determination in Health Studies. A practical manual. WHO, Geneva.

WHO/UNICEF/UNU (2001) Iron Deficiency Anaemia: Assessment, Prevention and Control: A Guide for Programme Managers. WHO. Geneva.

Williamson, C.S. (2006) Nutrition in pregnancy Briefing paper. Nutrition Bulletin. 31, 28 $-59$. 